\title{
Investigations on the Effect of Tool Types on the Mechanical Properties of Friction Stir Processed AZ31B Magnesium Alloy
}

\author{
K. Ganesa Balamurugan ${ }^{1}$, K. Mahadevan ${ }^{2}$, D. Peter Pushpanathan ${ }^{3}$ \\ ${ }^{1}$ Research Scholar, Dept. of Mechanical Engineering, Pondicherry Engineering College, Pondicherry -605014, \\ India. \\ ${ }^{2}$ Professor, Dept. of Mechanical Engineering, Pondicherry Engineering College, Pondicherry -605014, India. \\ ${ }^{3}$ Assistant Professor, Dept. of Mechanical Engineering, Christ College of Engineering \& Technology, \\ Pondicherry -605010, India.
}

\begin{abstract}
The present study investigates the effect of tool shoulder profile on the mechanical properties of friction stir processed AZ31B magnesium alloy The chosen process parameters are tool rotational speed and feed rate. The experiments were conducted with 3 level 2 factors full factorial design with two replications for both the tools. The tensile strength and micro hardness were the responses. The study reveals that, the properties of the materials processed with concave shoulder tool were governed by strain hardening effect. Likewise, the properties of the materials processed with the step shoulder tool were governed by the grain size.

Keywords: FSP, AZ31B alloy, Tool profile, Dislocation density, Grain size, ANOVA.
\end{abstract}

\section{Introduction}

Magnesium alloys are the most attractive materials in recent transportation industries where weight reduction is of prime importance [1-3]. Magnesium alloys are 35\% lighter than aluminium alloys and 78\% lighter than steel [4-6]. However, the mechanical properties of magnesium alloys are not commendable [7]. This limitation restricts the usage of magnesium alloys in many end applications. Recently some researchers [8] have identified friction stir processing (FSP) as a suitable technique to overcome the above mentioned limitations. FSP is a solid state processing technique for micro structural modification. FSP is an evolution technique of the friction stir welding process which was developed by The Welding Institute, U.K. In FSP, a rotating tool is plunged into a substrate to produce a highly plastically deformed zone consisting of refined grains generated due to recrystallization. Nevertheless, the material flow, uniformity of microstructure and the resulting properties at the processed zone are governed by the tool profile [9]. Present study investigates the effect of tool profiles on the mechanical properties like tensile strength and hardness of the FSP hot rolled AZ31B magnesium alloy. Two different tools one with a concave shoulder and other with step shoulder were used for the study. Tool rotational speed and feed rate were chosen as the process parameters.

\section{Experimental Procedure}

Commercial AZ31B alloy plates of 50x150x6 mm size were used in this study. Conventional vertical milling machine was used to perform the FSP on the plates. Two types of tools with different shoulder profile were used in this investigation. Fig 1a shows concave shoulder tool of $18 \mathrm{~mm}$ shoulder diameter and $5 \mathrm{~mm}$ pin diameter with strait flutes. The step shoulder tool with shoulder diameter of $18 \mathrm{~mm}$ and pin diameter of $5 \mathrm{~mm}$ with straight flutes is shown in fig $1 \mathrm{~b}$. The pin profile was maintained as same for both the tools. The tool material was $\mathrm{HCHCr}$ hardened to $58 \mathrm{HRC}$. The processing AZ31B magnesium plates were clamped on the machine table using a special fixture. Once the tool was plunged into the specimen, the automatic feed mechanism was engaged for further travel with preset feed rate. A constant tool depth of $3.1 \mathrm{~mm}$ was maintained throughout the process. The experiments were conducted on the basis of 2 factors 3 levels full factorial design with two replications for both types of tools. The range of tool rotational speed and feed used in this study are given in the Table1. The processed AZ31B magnesium alloy plates were subjected to mechanical tests like tensile test, micro hardness test and metallographic characterization as per ASTM standards. Tensile tests were conducted as per ASTM B557, micro hardness test as per ASTM E384; metallographic characterizations were done as per ASTM E407 and grain sizes were calculated as per ASTM E112. 


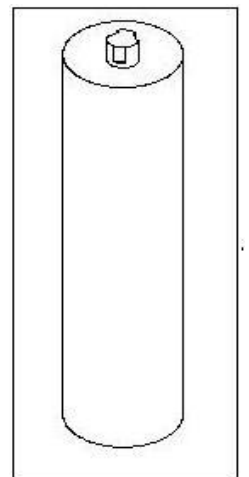

(a)

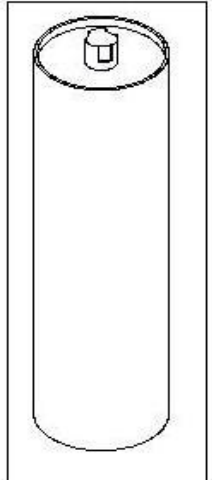

(b)

Figure 1 .a) Concave tool b) Step tool

Table 1 Process parameters and their values

\begin{tabular}{ccc}
\hline S1.No. & Tool Rotational Speed [RPM] & Tool Feed $[\mathrm{mm} / \mathrm{min}]$ \\
\hline 01 & 500 & 14.2 \\
02 & 710 & 20.6 \\
03 & 1000 & 28.5 \\
\hline
\end{tabular}

III. Results and Discussion

\subsection{Tensile strength:}

(a)

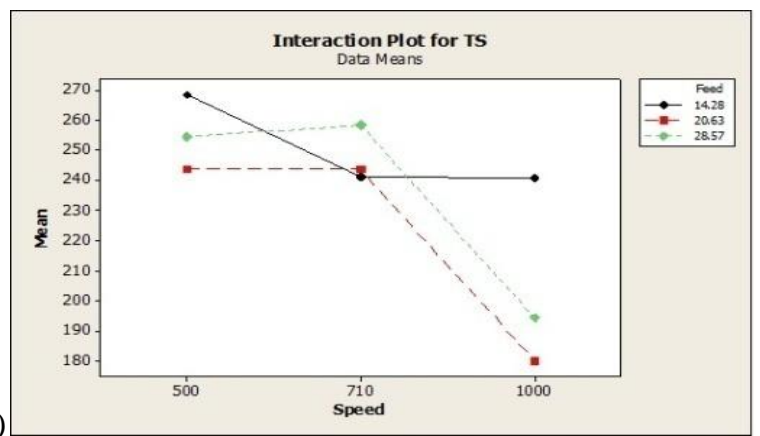

Fig.2 Tensile strength interaction plots (a) Concave Shoulder tool (b) Step Shoulder tool

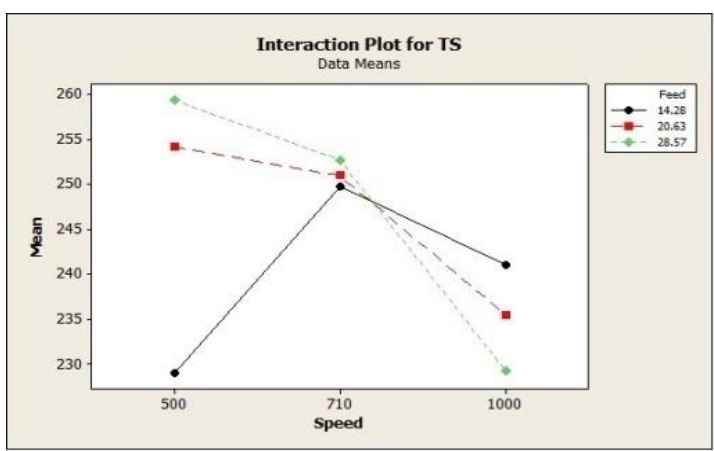

Figure 2 shows the interaction effect of rotational speed and feed rate on tensile strength of FSP AZ31B alloy with concave shoulder tool and step shoulder tool. Figure 2a shows the interaction effect of rotational speed and feed rate on FSP AZ31B alloy with concave shoulder tool and Figure $2 \mathrm{~b}$ shows the interaction effect of rotational speed and feed rate on FSP AZ31B alloy with step shoulder tool. From figure 2a it was observed that, AZ31B alloy processed with concave shoulder tool produces higher tensile strength at lower rotational speed and lower feed rate. Lower rotational speed and higher feed rate combinations produce better tensile strength values than higher rotational speed and higher feed rate combinations. At low tool rotational speed, there is increase in pile up of dislocation densities due to strain hardening effect. Nevertheless, at high tool rotational speed the high heat input checks the quantum of dislocation density making the specimen softer and thus reduces the strain hardening effect [10].

From figure $2 \mathrm{~b}$ it was observed that, AZ31B alloy processed with step shoulder tool produces higher tensile strength at low rotational speed and high feed rate. Tensile strength of the processed AZ31B alloy increases with increase in feed rate at low rotational speed. Contrarily, at higher rotational speed, tensile strength decreases with increase in feed rate. In case of step shoulder, major role was played by grain size to determine the tensile strength of the processed AZ31B alloy. At low tool rotational speeds, increase in feed rate produces coarse grains. This is due to insufficient time to deform the grains at higher feed rates. But at higher rotational speeds, increase in feed rate better refined grains could be achieved due to sufficient heat supplied by high rotational speed and rapid solidification of grains due to high feed rate. 


\subsection{Microhardness:}

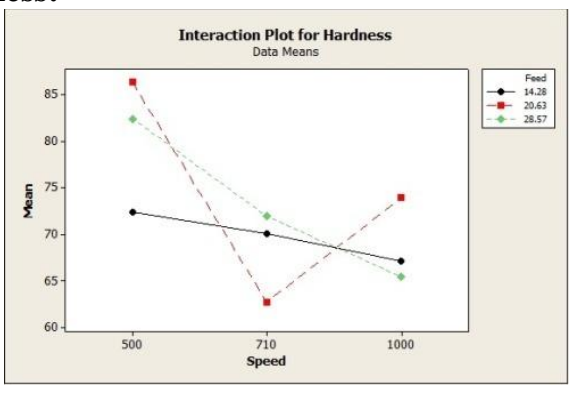

(b)

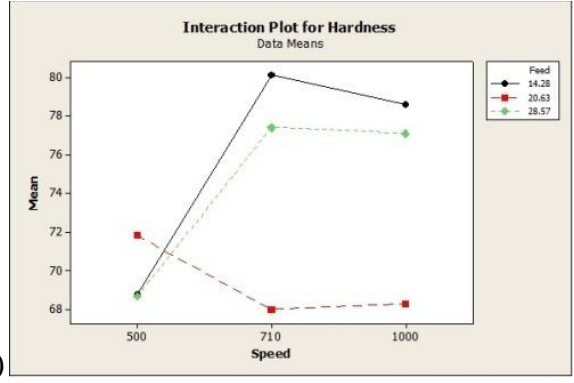

(a)

Fig.3 Microhardness interaction plots (a) Concave Shoulder tool (b) Step Shoulder tool

Figure 3a shows the interaction effect of rotational speed and feed rate on microhardness of the FSP AZ31B alloy with concave shoulder tool. From the figure 3a, it was observed that, the increase in rotational speed decreases the micro hardness of the processed material. The strain hardening effect leads to increase in microhardness of the AZ31B magnesium plates processed at lower speed and vice versa which is line with the results for tensile strength. Figure $3 b$ shows the interaction effect of rotational speed and feed rate on the FSP AZ31B alloy with step shoulder tool. From the figure $3 b$, it was observed that, the increase in rotational speed increases the micro hardness of the processed material. Microhardness of the processed materials decreases with grain refinement and it could be revealed by the micrographs shown in fig 4 . The sample processed at tool rotational speed of $500 \mathrm{rpm}$ and tool feed of $14.2 \mathrm{~mm} / \mathrm{min}$ has the microhardness value of $68.8 \mathrm{Hv}$ and its corresponding grain size average is shown in fig 4a. Similarly, the sample processed at tool rotational speed of $1000 \mathrm{rpm}$ and $14.2 \mathrm{~mm} / \mathrm{min}$ has the microhardness value of $78.6 \mathrm{Hv}$ and its corresponding grain size average is shown in fig $4 \mathrm{~b}$. It is obvious that, decrease in grain size decreases the microhardness values of FSP AZ31B alloy. In case of AZ31B alloy FSP with step shoulder tool, increase in material hardness due to FSP would not affect the improvement in ductility of the material. But in case of AZ31B alloy FSP with concave shoulder tool, increase in material hardness decreases the ductility of the processed material. This shows that both micro hardness and ductility can be improve by FSP with step shoulder tool on AZ31B alloy.

(a)

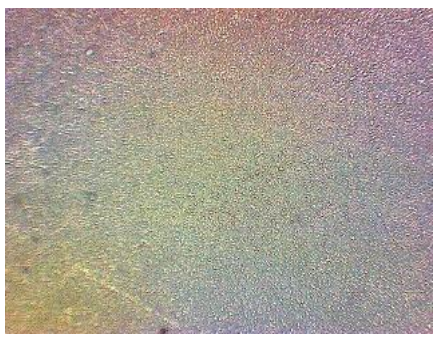

$<3$ microns (b)

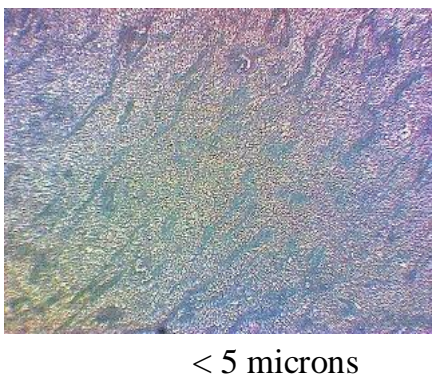

Fig.4 Microstructres of FSP AZ31B alloy processed with Step shoulder tool (a) $500 \mathrm{rpm}-14.2 \mathrm{~mm} / \mathrm{min}$, (b) 1000 $\mathrm{rpm}-14.2 \mathrm{~mm} / \mathrm{min}$

\subsection{Identification of significant factor:}

The significant factor of this experiment was identified using ANOVA technique. Using Minitab software, for $\alpha=0.95$ significance, the ANOVA tables were generated. Table 2 depicts the ANOVA results of mechanical properties of materials processed using Concave shoulder tool. From the ANOVA, the tool rotational speed was identified as significant factor for both responses. The ANOVA tables for tensile strength and microhardness are given in Table 2.

Table 2 ANOVA for mechanical properties of processed materials with Concave shoulder tool

\begin{tabular}{|c|c|c|c|c|c|c|c|c|}
\hline \multicolumn{9}{|c|}{ Analysis of Variance for Tensile Strength (Mpa), using Adjusted SS for Tests } \\
\hline Source & DF & Seq SS & Adj SS & Adj MS & & $\mathrm{F}$ & $\mathrm{P}$ & \\
\hline Speed(RPM) & 2 & 4053.6 & 4053.6 & 2026.8 & & 8.88 & 0.007 & \\
\hline Feed(mm per min) & 2 & 1268.2 & 1268.2 & 634.1 & & 2.78 & 0.115 & \\
\hline Speed(RPM)*Feed(mm per min) & 4 & 1154.3 & 1154.3 & 288.6 & & 1.26 & 0.352 & \\
\hline Error & 9 & 2054.8 & 2054.8 & 228.3 & & & & \\
\hline Total & 17 & 8530.9 & & & & & & \\
\hline \multicolumn{9}{|c|}{ Analysis of Variance for Hardness (Hv), using Adjusted SS for Tests } \\
\hline Source & $\mathrm{DF}$ & Seq SS & & Adj SS & Adj MS & & $\mathrm{F}$ & $\mathrm{P}$ \\
\hline Speed(RPM) & 2 & 468.83 & & 468.83 & 234.42 & & 90.43 & 0.000 \\
\hline Feed(mm per min) & 2 & 34.13 & & 34.13 & 17.06 & & 6.58 & 0.017 \\
\hline
\end{tabular}


Investigations on the effect of tool types on the mechanical properties of Friction Stir Processed

\begin{tabular}{|c|c|c|c|c|}
\hline Speed(RPM)*Feed(mm per min) & $\overline{44}$ & 343.35 & $\begin{array}{ll}343.35 \quad 85.84 \\
\end{array}$ & 33.11 \\
\hline Error & 9 & 23.33 & 23.33 & \\
\hline Total & 17 & 869.64 & & \\
\hline
\end{tabular}

Table 3 depicts the ANOVA results of mechanical properties of materials processed using Step shoulder tool. From the ANOVA, the tool rotational speed was identified as significant factor for tensile strength and for microhardness, feed rate was identified as significant factor. The ANOVA tables for tensile strength and microhardness are given in Table 3.

Table 3 ANOVA for mechanical properties of processed materials with Step shoulder tool

\begin{tabular}{|lclllll|}
\hline \multicolumn{2}{l}{ Analysis of Variance for Tensile } & Strength & (Mpa), using & Adjusted SS for Tests & & \\
Source & DF & Seq SS & Adj SS & Adj MS & F & P \\
Speed(RPM) & 2 & 695.06 & 695.06 & 347.53 & 87.15 & 0.000 \\
Feed(mm per min) & 2 & 121.43 & 121.43 & 60.71 & 15.22 & 0.001 \\
Speed(RPM)*Feed(mm per min) & 4 & 995.48 & 995.48 & 248.87 & 62.41 & 0.000 \\
Error & 9 & 35.89 & 35.89 & 3.99 & & \\
Total & 17 & 1847.86 & & & & \\
Analysis of Variance for Hardness (Hv), using Adjusted SS for Tests & & & P \\
Source & DF & Seq SS & Adj SS & Adj MS & F & \\
Speed(RPM) & 2 & 89.33 & 89.33 & 44.668 & 21.84 & 0.000 \\
Feed(mm per min) & 2 & 102.43 & 102.43 & 51.216 & 25.05 & 0.000 \\
Speed(RPM)*Feed(mm per min) & 4 & 123.91 & 123.91 & 30.979 & 15.15 & 0.000 \\
Error & 9 & 18.40 & 18.40 & 2.045 & & \\
$\quad$ Total & 17 & 334.08 & & & & \\
\hline
\end{tabular}

\section{Conclusion}

In this investigation an attempt was made to study the effect of tool types on the mechanical properties of friction stir processed AZ31B magnesium alloy. The following conclusions are derived.

1. The AZ31B materials processed by concave shoulder tool, strain hardening effect plays important role on the properties of the processed materials.

2. The AZ31B materials processed by step shoulder tool, the grain size plays important role on the properties of the processed materials.

3. Both micro hardness and ductility can be improved using FSP with step shoulder tool on AZ31B alloy.

4. This investigation reveals that, difference in tool types would result in changes in properties in the friction stir processed AZ31B Magnesium alloys.

\section{References}

[1] Yu Sirong, Chen Xianjun, Huang Zhiqiu, Liu Yaohui, Microstructure and mechanical properties of friction stir welding of AZ31B magnesium alloy added with cerium, Journal of rare earths, Vol. 28, No. 2, (2010), p.316-320.

[2] Mordike B L, Ebert T, Magnesium properties-applications potential, Materials Science and Engineering A (2001) Vol. 302 , p 37.

[3] Kinji Hirai, Hidetoshi Somekawa, Yorinobu Takigawa, Kenji Higashi, Effects of Ca and Sr addition on mechanical properties of a cast AZ91 magnesium alloy at room and elevatedtemperature, Materials Science and Engineering A (2005), Vol.403, p276.

[4] Parviz Asadi \& Ghader Faraji \& Mohammad K. Besharati, Producing of AZ91/SiC composite by friction stir processing (FSP), International Journal of Advanced Manufacturing Technology (2010) Vol. 51, p247-260.

[5] Morisada Y, Fujji H, Nagaoka T, Fukusumi M, Effect of friction stir processing with SiC particles on microstructure and hardness of AZ31, Material Science and Engineering A (2006) Vol. 433, p50-54.

[6] Darras BM, Khraisheh MK, Abu-Farha FK, Omar MA, Friction stir processing of commercial AZ31 magnesium alloy Material Processing Technology (2007) Vol.191, p77-81.

[7] P. Cavaliere, P.P. De Marco, Friction stir processing of AM60B magnesium alloy sheets, Materials Science and Engineering A (2007) Vol.462, p393-397.

[8] S. Mironov, Q. Yang, H. Takahashi, I. Takahashi, K. Okamoto, Y.S. Sato, and H.Kokawa, Specific Character of Material Flow in Near-Surface Layer during Friction Stir Processing of AZ31 Magnesium Alloy, The Minerals, Metals \& Materials Society and ASM International (2010) Vol. 41A, p1016-1024.

[9] R.S. Mishra, Z.Y. Ma, Friction stir welding and processing, Materials Science and Engineering R 50 (2005) 1-78

[10] George E.Dieter: Mechanical Metallurgy (second edition, McGraw-Hill publication). 